\title{
The Preparation of High-Volume Fraction SiC/Al Composites with High Thermal Conductivity by Vacuum Pressure Infiltration
}

\author{
Mengqin Chen ${ }^{1,2,3}$, Yuelong Bai ${ }^{1,2,3,4, *}$, Zhifeng Zhang ${ }^{1,2,3,4, *}$ and Haidong Zhao ${ }^{5}$ \\ 1 National Engineering \& Technology Research Center for Nonferrous Metals Composites, GRINM Group Co., \\ Ltd., Beijing 100088, China; MengqinChencatt@outlook.com \\ 2 Grinm Metal Composites Technology Co., Ltd., Beijing 101407, China \\ 3 General Research Institute for Nonferrous Metals, Beijing 100088, China \\ 4 GRIMAT Engineering Institute Co., Ltd., Beijing 101407, China \\ 5 National Engineering Research Center for Metallic Materials Net-Shape Forming, South China University of \\ Technology, Guangzhou 510641, China; hdzhao@scut.edu.cn \\ * Correspondence: baiyuelong@grinm.com (Y.B.); zhangzf@grinm.com (Z.Z.); Tel.: +86-1381-058-5961 (Y.B.); \\ +86-1352-290-0206 (Z.Z.)
}

Citation: Chen, M.; Bai, Y.; Zhang, Z.; Zhao, H. The Preparation of

High-Volume Fraction SiC/Al

Composites with High Thermal Conductivity by Vacuum Pressure Infiltration. Crystals 2021, 11, 515. https://doi.org/10.3390/cryst11050515

Academic Editors: Tomasz Sadowski and Leonid Kustov

Received: 1 April 2021

Accepted: 1 May 2021

Published: 6 May 2021

Publisher's Note: MDPI stays neutral with regard to jurisdictional claims in published maps and institutional affiliations.

Copyright: (C) 2021 by the authors. Licensee MDPI, Basel, Switzerland. This article is an open access article distributed under the terms and conditions of the Creative Commons Attribution (CC BY) license (https:// creativecommons.org/licenses/by/ $4.0 /)$.

\begin{abstract}
The high-volume fraction $\mathrm{SiC} / \mathrm{Al}$ composite is the new type of electronic packaging material, which plays an important role in the field of high-power integrated circuits. In this study, $\mathrm{SiC} / \mathrm{Al}$ composites with high-volume fraction of $\mathrm{SiC}$ particles were prepared by vacuum pressure infiltration. The influence of $\mathrm{SiC}$ particle size and $\mathrm{NH}_{4} \mathrm{HCO}_{3}$ on the pores in the preform was explored, aiming to accurately adjust the volume fraction of $\mathrm{SiC}$ to meet the thermal performance requirements in different fields. In addition, the preform was infiltrated with different $\mathrm{Al}$ alloys, and the relationship between the porosity and thermal conductivity of SiC/Al was studied. For the $\mathrm{SiC}$ preform, the volume fraction of $\mathrm{SiC}$ can be adjusted regularly when $12 \mu \mathrm{m}$ and $100 \mu \mathrm{m} \mathrm{SiC}$ particles are mixed in different proportions, and the volume fraction reaches the maximum when the proportion of coarse particles is about $77 \% . \mathrm{NH}_{4} \mathrm{HCO}_{3}$ is conducive to the connectivity of pores in the preform, and about 40 vol.\% of $\mathrm{NH}_{4} \mathrm{HCO}_{3}$ can effectively increase the porosity of the preform. Thermal conductivity is sensitive to the porosity of composites, especially in the range of $2.5-4.5 \%$. A simple application of the Hasselman-Johnson model and a new thermal conductivity model, $\lambda_{d}$, established in this article, offer a good agreement with the experimental results.
\end{abstract}

Keywords: $\mathrm{SiC} / \mathrm{Al}$; volume fraction; infiltration; pore; thermal conductivity

\section{Introduction}

With the rapid development of electronic science and technology, the high integration of chips and the miniaturization of packaging put forward higher requirements for electronic packaging materials [1]. High-volume fraction SiC/ Al composites (the volume fraction of $\mathrm{SiC}$ is more than $50 \mathrm{vol} \%$ ) have attracted much attention in the field of aerospace, rail transit, automobile, and other high-power integrated circuits, which need fast heat dissipation and matching expansion coefficient, due to their excellent thermal conductivity, low expansion coefficient, low density, and designability [2,3]. However, many previous works have focused on the preparation of SiC / Al composites with low volume fraction, and the preparation of high-volume fraction composites containing more than $50 \mathrm{vol} \% \mathrm{SiC}$ particles have not been fully studied. Moreover, with the introduction of a large number of $\mathrm{SiC}$ particles, the machining of $\mathrm{SiC} / \mathrm{Al}$ composites becomes increasingly harsh. It is necessary to explore a near net forming technology for the composites [4,5]. Compared with powder metallurgy and the stirring casting method [6,7], the vacuum pressure infiltration method has characteristics including short infiltration time, near net shape, and 
low cost, which is why it is the most competitive method to prepare high-volume $\mathrm{SiC} / \mathrm{Al}$ composites $[8,9]$.

Vacuum pressure infiltration method mainly includes two processes, namely, the preparation of the $\mathrm{SiC}$ preform and the infiltration of liquid $\mathrm{Al}$ into the preform $[3,10]$. The porosity and pore characteristics (pore size and connectivity) of the preform determine the microstructure of the composite directly. For an ideal SiC preform, the volume fraction of $\mathrm{SiC}$ must be easily controlled, and the pores in the preform need to be connected [11]. $\mathrm{SiC} / \mathrm{Al}$ composites with different volume fractions can be prepared by combining $\mathrm{SiC}$ particles with various sizes or adding pore forming agents [12-15]. These two ways also change the pore characteristics of the preform $[15,16]$. For the process of $\mathrm{Al}$ liquid infiltration, clarifying the properties of $\mathrm{Al}$, such as its fluidity and wettability with $\mathrm{SiC}$, are helpful to further improve the performance of $\mathrm{SiC} / \mathrm{Al}$ [17]. The majority of current research focuses on the properties of liquid $\mathrm{Al}$ in pressureless infiltration [18-20]. There are few studies on the infiltration behavior of liquid $\mathrm{Al}$ under vacuum pressure infiltration. Lee et al. [21] successfully infiltrated liquid $\mathrm{Al}$ into the preform by changing vacuum pressure infiltration parameters. For $\mathrm{SiC} / \mathrm{Al}$ composites, the porosity is an unavoidable phase, which is intrinsically related to the poor wetting characteristics of the interface [22]. For the two characteristics of interest in the field of electronic packaging, namely thermal expansion coefficient and thermal conductivity, it has been proven that for different systems, the former rarely, or does not at all, depend on the porosity of SiC/ $\mathrm{Al}$ [23]. On the contrary, the porosity may greatly reduce the thermal conductivity of $\mathrm{SiC} / \mathrm{Al}$. Therefore, it is necessary to study the relationship between porosity and thermal conductivity [22,24]. With the development of the research on $\mathrm{SiC} / \mathrm{Al}$ composites, researchers have gradually realized the influence of interface, phase composition, particle size, and other factors on the thermal conductivity $[15,25,26]$. They have established different models to predict the thermal conductivity of composites which deepen the researchers' understanding of $\mathrm{SiC} / \mathrm{Al}$ and reduce the test cost [27].

In this work, the vacuum pressure infiltration method for preparing high-volume fraction $\mathrm{SiC} / \mathrm{Al}$ composites was studied. The adjustment of pores in the $\mathrm{SiC}$ preform and the influence of the $\mathrm{Al}$ alloy element are emphasized in this article. The relationship between porosity and thermal conductivity of composites is also discussed, and based on the Hasselman-Johnson model, a new prediction model of thermal conductivity for composites with $2-8 \%$ porosity is established.

\section{Materials and Methods}

\subsection{Materials}

Green $\alpha$-SiC powders with mean particle sizes of 12 and $100 \mu \mathrm{m}$ were used as reinforcements in this study, the theoretical density was $3.2 \mathrm{~g} / \mathrm{cm}^{3}$. Al-7Si-Mg and Al-12Si-Mg were selected as matrix alloys, in which the content of $\mathrm{Mg}$ was only about $0.3 \mathrm{wt} . \%$. Ammonium bicarbonate with the molecular formula of $\mathrm{NH}_{4} \mathrm{HCO}_{3}$ (analytical purity), the theoretical density of $1.58 \mathrm{~g} / \mathrm{cm}^{3}$ (Tianjin Bailunsi Biotechnology Co., Ltd.), was used as pore forming agent [28]. Ammonium dihydrogen phosphate was used as binder with the molecular formula of $\mathrm{NH}_{4} \mathrm{H}_{2} \mathrm{PO}_{4}$ (analytical purity) and the theoretical density of $1.803 \mathrm{~g} / \mathrm{cm}^{3}$ (Tianjin Fuchen chemical reagents factory) [29]. Anhydrous ethanol was used for surface cleaning of $\mathrm{SiC}$ particles with molecular formula of $\mathrm{CH}_{3} \mathrm{CH}_{2} \mathrm{OH}$ (analytical purity) (Beijing Chemical Works).

\subsection{Experiments}

The experiment of preparing $\mathrm{SiC} / \mathrm{Al}$ composites by vacuum pressure infiltration method includes two predominant processes: the preparation of $\mathrm{SiC}$ preforms and the infiltration of liquid $\mathrm{Al}$ alloy into the pores of the preforms. Figure 1 shows the method. 


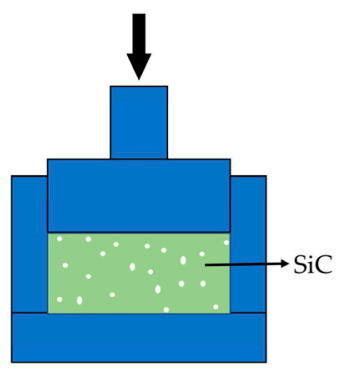

Compression molding

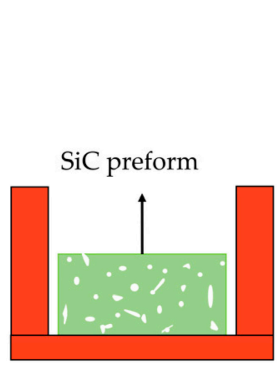

heating

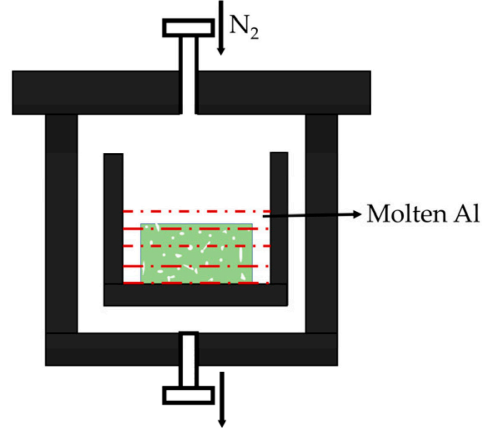

Al liquid infiltration

Figure 1. Illustration of the preparation of high-volume fraction $\mathrm{SiC} / \mathrm{Al}$ by the liquid infiltration method.

The preparation process of the $\mathrm{SiC}$ preform is as follows: firstly, the $\mathrm{SiC}$ particles are cleaned by ultrasonic wave with ethanol to remove the surface impurities. According to the designed proportion, the cleaned $\mathrm{SiC}$ particles, $\mathrm{NH}_{4} \mathrm{H}_{2} \mathrm{PO}_{4}$ and $\mathrm{NH}_{4} \mathrm{HCO}_{3}$, are stirred and mixed evenly. We filled the mold with these mixed materials, and the mixture was shaped with mechanical pressure (40 Mpa). Then, the pressed SiC preform blank was slowly heated to $700{ }^{\circ} \mathrm{C}$, so that the pore former can be fully volatilized to leave pores (it can be completed at about $145^{\circ} \mathrm{C}$ ), and the binder was thermally degreased to ensure the high temperature strength of the $\mathrm{SiC}$ preform [29]. In this work, the influences of the ratio of 2 kinds of $\mathrm{SiC}$ particles and the content of pore forming agent $\mathrm{NH}_{4} \mathrm{HCO}_{3}$ on the volume fraction and internal pore characteristics of the $\mathrm{SiC}$ preform were investigated. The specific experimental parameters are shown in Tables 1 and 2.

Table 1. Experimental scheme of 2 kinds of SiC particles with different proportions.

\begin{tabular}{cccc}
\hline $\begin{array}{c}\text { Content Ratio of } \mathbf{1 0 0} \boldsymbol{\mu m} \\
\text { and } \mathbf{1 2} \boldsymbol{\mu m} \text { SiC Particles }\end{array}$ & $\begin{array}{c}\mathbf{N H}_{\mathbf{4}} \mathbf{H}_{\mathbf{2}} \mathbf{P O}_{4} \\
\text { Content/vol.\% }\end{array}$ & $\begin{array}{c}\mathbf{N H}_{\mathbf{4}} \mathbf{H C O}_{3} \text { Content } \\
\text { /vol.\% }\end{array}$ & $\begin{array}{c}\text { SiC Content } \\
\text { /vol.\% }\end{array}$ \\
\hline $0: 1$ & 5 & 25 & 70 \\
$1: 2$ & 5 & 25 & 70 \\
$1: 1$ & 5 & 25 & 70 \\
$2: 1$ & 5 & 25 & 70 \\
$3: 1$ & 5 & 25 & 70 \\
$4: 1$ & 5 & 25 & 70 \\
$5: 1$ & 5 & 25 & 70 \\
$7: 1$ & 5 & 25 & 70 \\
$10: 1$ & 5 & 25 & 70 \\
$1: 0$ & 5 & 25 & 70 \\
\hline
\end{tabular}

Table 2. Experimental scheme of the different content of $\mathrm{NH}_{4} \mathrm{HCO}_{3}$.

\begin{tabular}{ccc}
\hline $\begin{array}{c}\mathrm{NH}_{4} \mathrm{HCO}_{3} \text { Content } \\
\text { /vol.\% }\end{array}$ & $\begin{array}{c}\text { SiC Content } \\
\text { /vol.\% }\end{array}$ & $\begin{array}{c}\text { Content Ratio of } \mathbf{1 0 0} \mu \mathrm{m} \text { and 12 } \\
\mu \mathrm{m} \mathrm{SiC} \mathrm{Particles}\end{array}$ \\
\hline 0 & 100 & $10: 1$ \\
10 & 90 & $10: 1$ \\
20 & 80 & $10: 1$ \\
30 & 70 & $10: 1$ \\
\hline
\end{tabular}

The process of liquid $\mathrm{Al}$ infiltration is as follows: firstly, we put the prepared preform into a crucible, and the $\mathrm{Al}$ alloy was placed above the preform. After loading the crucible into the furnace, we vacuumed the whole device. When a certain vacuum degree was reached, the crucible was heated to the designed temperature to melt the $\mathrm{Al}$ alloy. Then, the device was filled with nitrogen to infiltrate the $\mathrm{Al}$ liquid into the preform under a certain 
pressure. After holding the pressure for a period of time, we took out the infiltrated sample. The technological parameters of liquid Al infiltration from this experiment are shown in Table 3.

Table 3. Technological parameters of liquid $\mathrm{Al}$ infiltration process.

\begin{tabular}{ccccc}
\hline Al Alloy & $\begin{array}{c}\text { Infiltration } \\
\text { Pressure (Mpa) }\end{array}$ & $\begin{array}{c}\text { Infiltration } \\
\text { Temperature }\left({ }^{\circ} \mathbf{C}\right)\end{array}$ & $\begin{array}{c}\text { Infiltration } \\
\text { Time (min) }\end{array}$ & $\begin{array}{c}\text { Vacuum Degree } \\
\mathbf{( P a )}\end{array}$ \\
\hline $\begin{array}{c}\text { Al-7Si-Mg } \\
\text { Al-12Si-Mg }\end{array}$ & 1.1 & 800 & 10 & 100 \\
\hline
\end{tabular}

\subsection{Characterization}

A field emission scanning electron microscope (SEM), JSM-7610F, was used to observe the microstructure and pores of the $\mathrm{SiC}$ preform and the microstructure and morphology of $\mathrm{SiC} / \mathrm{Al}$ composite. The phase identification, micro element type, and composition of the $\mathrm{SiC}$ preform and composite were carried out by smartlab X-ray diffraction (XRD) and energy dispersive $\mathrm{X}$-ray spectrometer (EDS). The actual density of the SiC preform was measured by the mass volume method, and the volume fraction of $\mathrm{SiC}$ particles and the porosity of the SiC preform were calculated. The Archimedes drainage method was used to measure the actual density of $\mathrm{SiC} / \mathrm{Al}$ composites. The specific steps refer to the national standard GB/T 3850-2015. The density and porosity of SiC/Al composites were obtained by calculating the ratio of actual density to theoretical density. According to the national standard GB/T 22588-2008, the thermal conductivity of SiC/Al composites was measured by Netzsch LFA467 thermal conductivity tester. The number of test samples for porosity and thermal conductivity is 3 , and the average value is taken after measurement.

\section{Results and Discussion}

\subsection{Volume Fraction and Pore Characteristics of SiC Preforms}

\subsubsection{SiC Preform with a Bimodal Size Distribution (12 and $100 \mu \mathrm{m})$}

High-volume fraction $\mathrm{SiC}$ preforms were made by mixing SiC particles with mean diameters of 12 and $100 \mu \mathrm{m}$, as shown in Table 1. It is considered that the apparent volume of the preform after sintering is the volume formed by $\mathrm{SiC}$ particles and pores, that is, $\mathrm{SiC}$ volume fraction $=1$-porosity. Figure 2 shows the experimental results for the SiC volume fraction of the preform versus the proportion of coarse particles $(100 \mu \mathrm{m})$ in the mixture. Undoubtedly, the volume fraction of $\mathrm{SiC}$ in the preform is about $56 \%$ using only the fine particles $(12 \mu \mathrm{m})$, and $62 \%$ using only the coarse particles. The volume fraction of $\mathrm{SiC}$ can be adjusted from $56 \%$ to $68 \%$ when $\mathrm{SiC}$ particles with bimodal size are mixed in different proportions. With the increase in coarse particles, the volume fraction of $\mathrm{SiC}$ increases first and then decreases. From the fitting curve in Figure 2, the preform with $77 \%$ of coarse particles shows the maximum volume fraction $(68 \%)$, which is $21 \%$ higher than that using only fine particles. It is worth noting that the extreme point is larger than that of most research in the bimodal size system [15]. Their results show that when the content of coarse particles is about $67 \%$, the volume fraction of SiC particles in the preform shows the maximum. The reasons for the differences are as follows: (1) in this work, additional pore forming agent was added. When under a molding pressure, the $\mathrm{NH}_{4} \mathrm{HCO}_{3}$ was further crushed, which changed the stacking mode of mixed particles, resulting in the maximum $\mathrm{SiC}$ volume fraction being obtained in different coarse proportions. It should be emphasized that the trends between the two results are consistent. In other words, with the increase in coarse particle proportion, the volume fraction of the preform increases first and then decreases. The role of the pore forming agent will also be mentioned in Section 3.1.2. The shape of particles and the difference of particle size ratio also caused some differences $[13,30,31]$. 


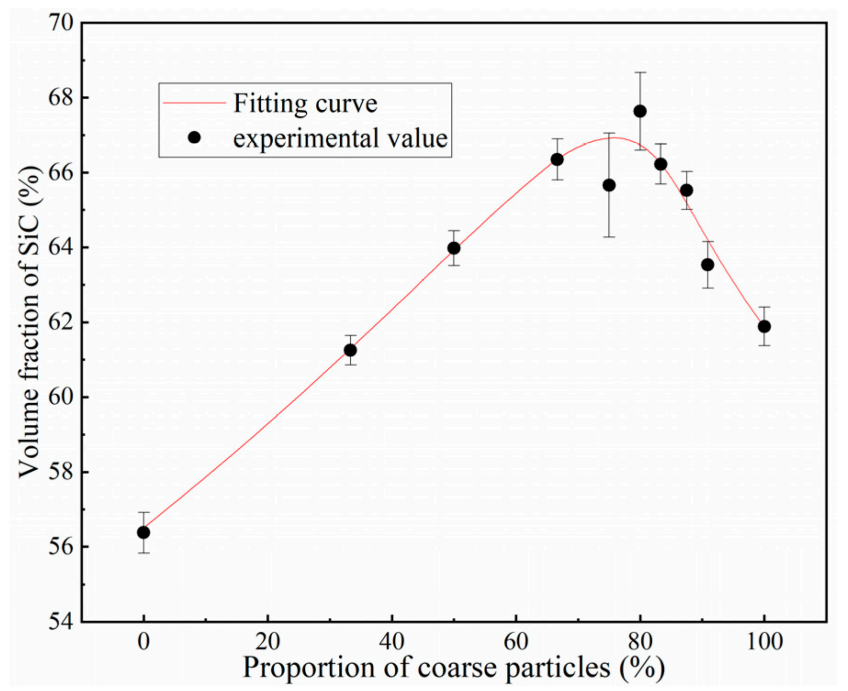

Figure 2. The relationship between the volume fraction of $\mathrm{SiC}$ and the proportion of coarse $\mathrm{SiC}$ particles $(100 \mu \mathrm{m})$.

In order to describe the pore characteristics of the preform with different proportions of coarse particles, the micro morphology of the $\mathrm{SiC}$ preform and the corresponding $\mathrm{SiC} / \mathrm{Al}$ composite was observed, as shown in Figure 3. It can be seen from Figure 3a that the irregular shape of $100 \mu \mathrm{m}$ coarse particles were randomly stacked to create loose pores, most of which were $20-30 \mu \mathrm{m}$ in diameter. When coarse and fine particles exist at the same time, as shown in Figure 3c, there are two stacking modes of the fine $\mathrm{SiC}$ particles: (1) squeezing between the coarse $\mathrm{SiC}$ particles causes the volume of the $\mathrm{SiC}$ preform to increase; (2) filling in the loose pores stacked by coarse particles, which does not cause the volume fraction of the preform to change. Therefore, in the first stage of Figure 2, with the increase in coarse particles, the number of pores stacked by coarse particles in the preform increases, and the fine particles will fill these pores, thus increasing the volume fraction of $\mathrm{SiC}$. When the proportion of coarse particles is greater than the critical value ( $77 \%$ as mentioned above), the increase in coarse particles leads to a decrease in SiC volume fraction. Fewer fine particles fill into the loose pores which coarse particles stacked, andthe volume fraction of $\mathrm{SiC}$ decreases until coarse particles are $100 \%$, that is the second stage of Figure 2. Therefore, the volume fraction of $\mathrm{SiC}$ can be adjusted accurately and effectively to satisfy different thermal performance requirements by the trend analyzed above.

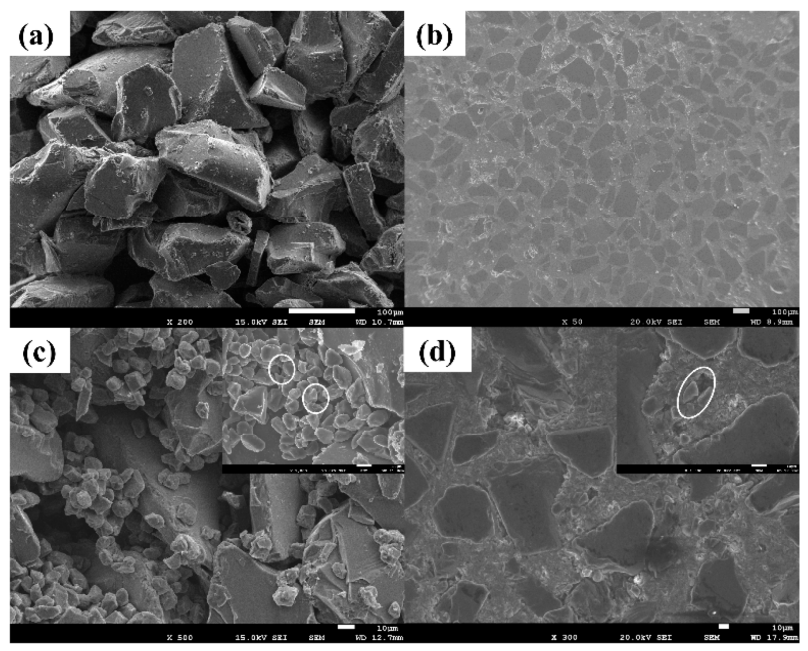

Figure 3. Representative SEM images showing the micromorphology of the SiC preforms and the corresponding $\mathrm{SiC} / \mathrm{Al}$ composites with coarse to fine particle ratios of $(\mathbf{a}, \mathbf{b})$ 1:0 and (c,d) 5:1. 
The internal pore characteristics of the preform are an important parameter, such as pore size and pore connectivity [32]. According to the expression of prediction model [33]:

$$
\Delta \mathrm{P}=\frac{-2 \mathrm{D}_{\mathrm{f}}}{\mathrm{r}}
$$

In Equation (1), $r$ represents the radius of the smallest pore that will be penetrated by the liquid, $\mathrm{D}_{\mathrm{f}}$ is the driving force for wetting. According to the equation, the driving force $(\Delta \mathrm{P})$ required for penetration is inversely proportional to the size of the pore in the preform. Therefore, under the same infiltration pressure, molten $\mathrm{Al}$ tends to penetrate the large pore channel preferentially. As shown in Figure $3 c$, the introduction of fine particles fills up the space between coarse particles, resulting in the pore size $(10-20 \mu \mathrm{m})$ significantly smaller than the loose pores $(20-30 \mu \mathrm{m})$ in Figure 3a. In addition, the pores formed by the fine particles are even smaller $(<5 \mu \mathrm{m})$, as shown by the circle in Figure 3c. Figure $3 \mathrm{~b}$,d is the $\mathrm{SiC} / \mathrm{Al}$ composite material infiltrated from the preform shown in Figure 3a,c under same infiltration pressure. As shown in Figure $3 \mathrm{~b}$, the $\mathrm{SiC} / \mathrm{Al}$ composite material with $100 \% 100 \mu \mathrm{m} \mathrm{SiC}$ preform is well infiltrated, which has uniform structure distribution and excellent interface bonding. On the contrary, the composite material in Figure $3 \mathrm{~d}$ has many pores and poor interface bonding. Pores are more likely to exist between small particles (such as the circle in Figure 3d). From the Equation (1), the small-sized pores formed between small particles are more difficult to be infiltrated under the same impregnation pressure. Therefore, the pore characteristics of the preform determine the infiltration results directly. When fine $\mathrm{SiC}$ particles are introduced to increase the volume fraction of the preform, the infiltration pressure should be increased accordingly.

\subsection{2. $\mathrm{SiC}$ Preform with Different Contents of Pore Forming Agent $\left(\mathrm{NH}_{4} \mathrm{HCO}_{3}\right)$}

The role of the pore forming agent is to adjust the porosity and pore characteristics of the $\mathrm{SiC}$ preform. In order to better understand how $\mathrm{NH}_{4} \mathrm{HCO}_{3}$ acts, different contents of $\mathrm{NH}_{4} \mathrm{HCO}_{3}$ were added to prepare the $\mathrm{SiC}$ preform (as shown in Table 2). The relationship between the porosity of the $\mathrm{SiC}$ preform and the content of $\mathrm{NH}_{4} \mathrm{HCO}_{3}$ is shown in Figure 4 . It can be seen that the addition of $\mathrm{NH}_{4} \mathrm{HCO}_{3}$ effectively increases the porosity of the $\mathrm{SiC}$ preform. According to the pyrolysis characteristics of $\mathrm{NH}_{4} \mathrm{HCO}_{3}$, it will decompose and release gas during the heating process, which forms pores in the preform. In addition, there is a remarkable linear relationship between the porosity of the $\mathrm{SiC}$ preform and the $\mathrm{NH}_{4} \mathrm{HCO}_{3}$ content. By fitting the data in Figure 4, the model of Equation (2) is established:

$$
\mathrm{Y}=26.9+0.4 \mathrm{X}
$$

where $\mathrm{Y}$ is the porosity of the $\mathrm{SiC}$ preform, and $\mathrm{X}$ represents $\mathrm{NH}_{4} \mathrm{HCO}_{3}$ content. Undoubtedly, the fitted curve offers a good agreement with the experimental results. In other words, when no $\mathrm{NH}_{4} \mathrm{HCO}_{3}$ is added, the original porosity of the preform is $26.9 \%$, and the increase in the porosity of the preform is about $40 \mathrm{vol} \%$ of that of the added $\mathrm{NH}_{4} \mathrm{HCO}_{3}$. Equation (2) provides a good calculation model and the volume fraction of the $\mathrm{SiC}$ preform can be controlled more accurately through it.

To further study the characteristics of the pores in the preform, the micromorphology of $\mathrm{SiC} / \mathrm{Al}$ composite with different content of $\mathrm{NH}_{4} \mathrm{HCO}_{3}$ was observed, as shown in Figure 5. It can be seen from Figure $5 \mathrm{a}, \mathrm{b}$ that there are many closed pores in the composite with $10 \% \mathrm{NH}_{4} \mathrm{HCO}_{3}$ in the experiment. In contrast, the infiltration result of the composite with $30 \% \mathrm{NH}_{4} \mathrm{HCO}_{3}$ is better, in which there is no obvious pore. It is considered that $\mathrm{NH}_{4} \mathrm{HCO}_{3}$ can increase the connectivity of pores. The action mechanism of the pore forming agent is analyzed as follows: the particle size of $\mathrm{NH}_{4} \mathrm{HCO}_{3}$ used in this experiment is less than $230 \mu \mathrm{m}$. During the molding process, $\mathrm{NH}_{4} \mathrm{HCO}_{3}$ is subjected to a certain pressure and further broken to smaller particles. As shown in Figure 6, pore forming agents of different sizes randomly adhere to the surface of $\mathrm{SiC}$ particles and occupy part of the space. After decomposition at high temperature, all the generated gases escape, 
and the corresponding positions become pores. The pore forming agent, which occupies the channel of $\mathrm{Al}$ liquid flowing through, decomposes to form pores, and then connects with other pores. Therefore, the increase in $\mathrm{NH}_{4} \mathrm{HCO}_{3}$ is conducive to the connection of preformed pores, so as to achieve a better infiltration result. In this case, the pore forming agent $\mathrm{NH}_{4} \mathrm{HCO}_{3}$ acts as a bridge to connect more pores.

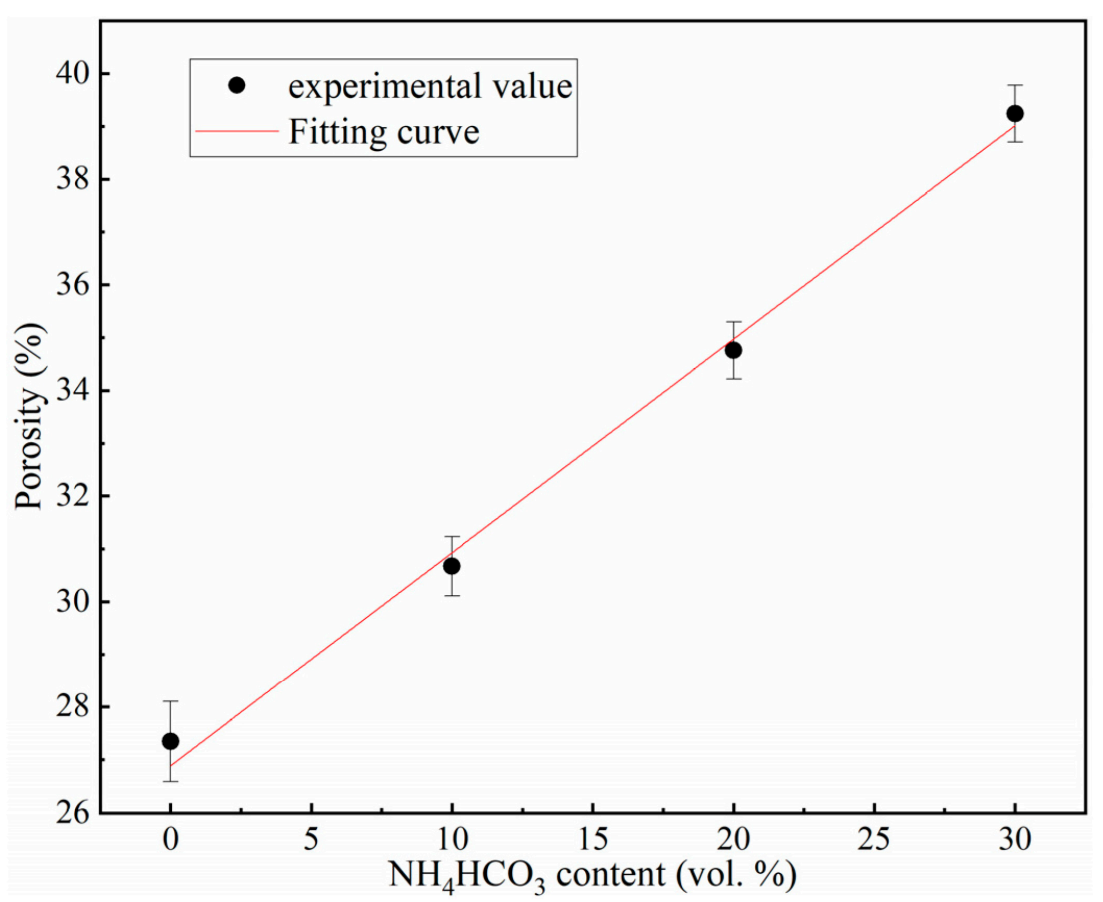

Figure 4. The relationship between the porosity of the $\mathrm{SiC}$ preform and the content of $\mathrm{NH}_{4} \mathrm{HCO}_{3}$.

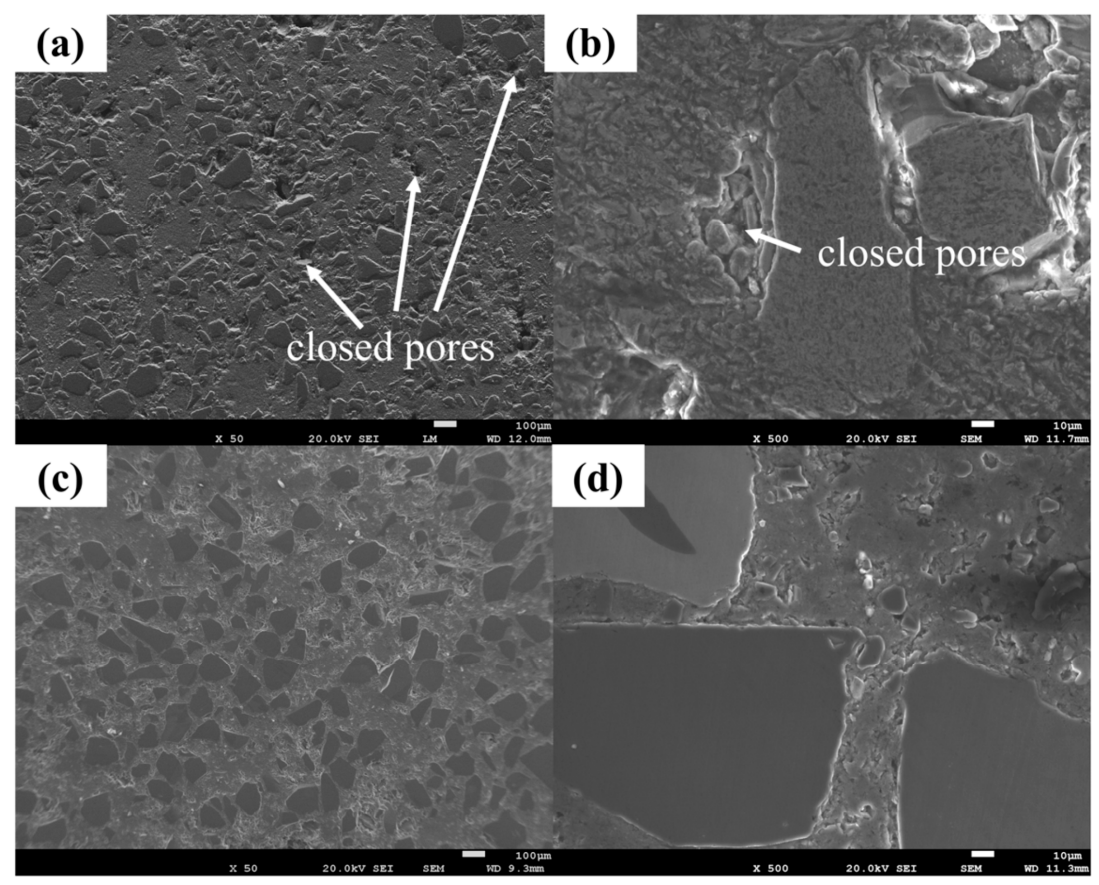

Figure 5. Representative SEM images showing the micromorphology of SiC/ $\mathrm{Al}$ composites with (a,b) $10 \%$; (c,d) $30 \% \mathrm{NH}_{4} \mathrm{HCO}_{3}$ added. 


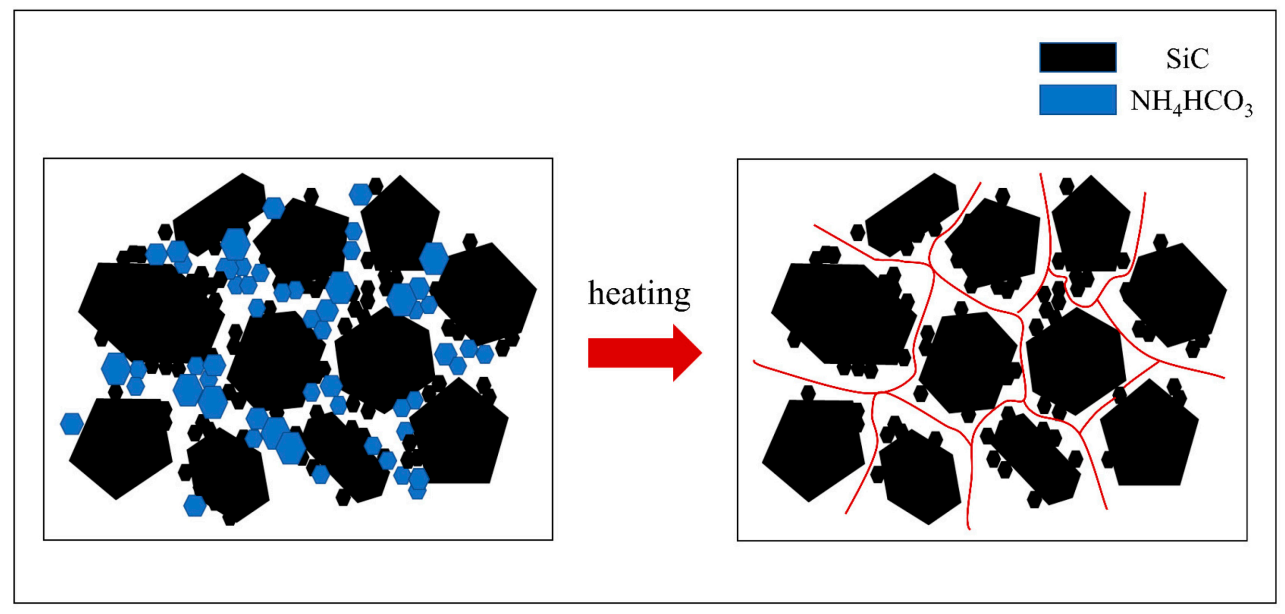

Figure 6. Illustration of the role of $\mathrm{NH}_{4} \mathrm{HCO}_{3}$ in the $\mathrm{SiC}$ preform.

\subsection{Infiltration of $\mathrm{SiC}$ Preform with $\mathrm{Al}$}

Al-7Si-Mg and Al-12Si-Mg (with less Mg content, about 0.3 wt.\%) were used to infiltrate the preforms with a different $\mathrm{SiC}$ volume fraction. Figure 7 shows the thermal conductivity of the composites infiltrated with Al-7Si-Mg and Al-12Si-Mg. It is clear that, using the alloy $\mathrm{Al}-12 \mathrm{Si}-\mathrm{Mg}$ with high $\mathrm{Si}$ content for infiltration, the thermal conductivity of the composite material is always greater than that of the alloy Al-7Si-Mg with low Si content. Generally, the increase in Si content will lead to the decrease in thermal conductivity of the matrix Al. In this work, although the thermal conductivity of the Al-12Si-Mg matrix is relatively low, the thermal conductivity of the composite material did not decrease. Figure 8 shows the microstructure of $\mathrm{SiC} / \mathrm{Al}-7 \mathrm{Si}-\mathrm{Mg}$ and $\mathrm{SiC} / \mathrm{Al}-12 \mathrm{Si}-\mathrm{Mg}$ composites. Comparing Figure $8 \mathrm{a}, \mathrm{c}$ and Figure $8 \mathrm{~b}$, $\mathrm{d}$, it can be observed that under the same conditions, the composite with Al-12Si-Mg is more completely infiltrated than the composite with Al-7Si-Mg. SiC/Al-12Si-Mg have fewer pores and better interface bonding. It can be considered that $\mathrm{Al}-12 \mathrm{Si}-\mathrm{Mg}$ is more conducive to infiltration.

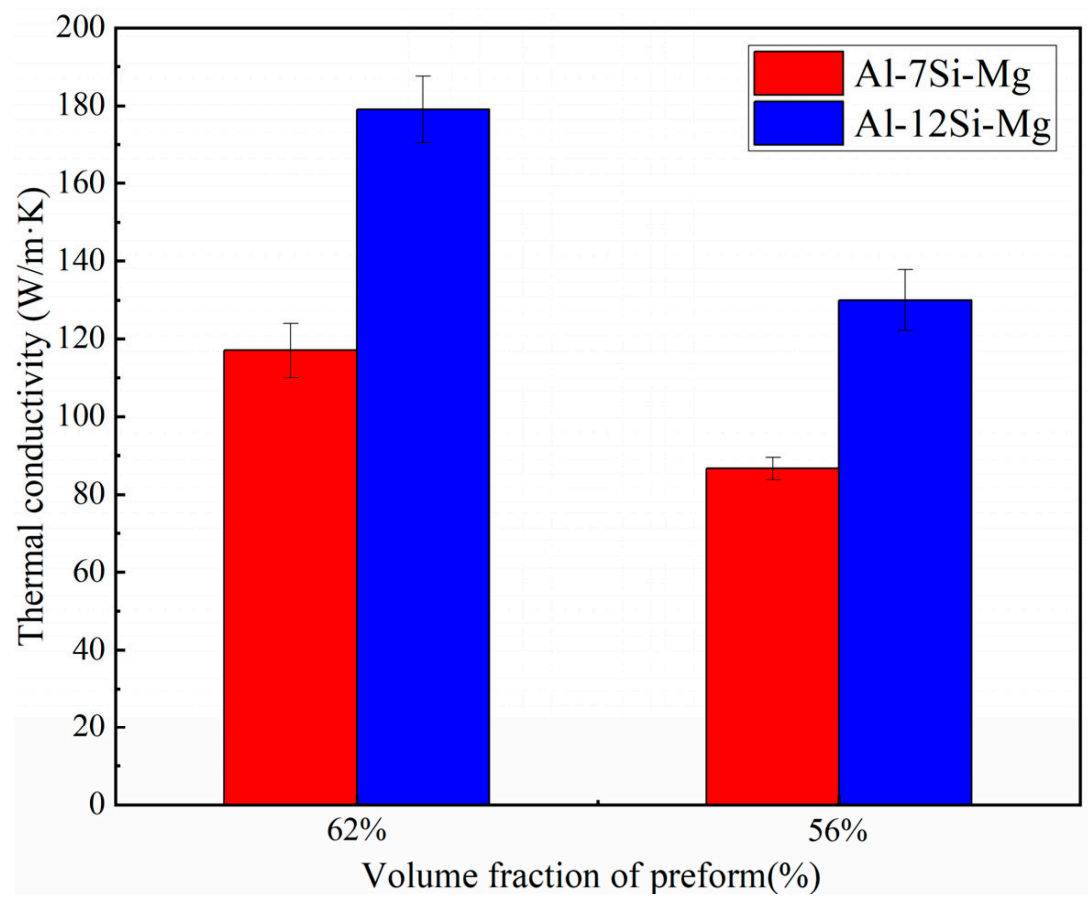

Figure 7. Thermal conductivity of composites infiltrated with Al-7Si-Mg and Al-12Si-Mg. 


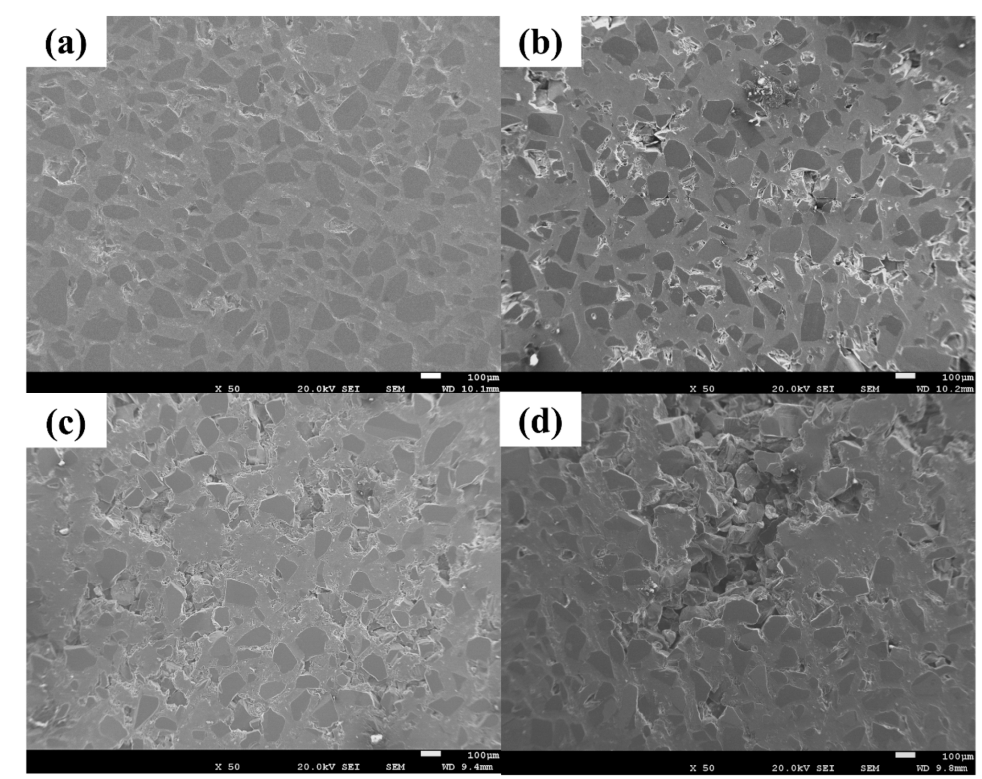

Figure 8. Representative SEM images showing the micromorphology of: (a) $\mathrm{SiC} / \mathrm{Al}-12 \mathrm{Si}-\mathrm{Mg}$ (62\% SiC); (b) SiC/Al-7Si-Mg (62\% SiC); (c) SiC/Al-12Si-Mg (56\% SiC); (d) SiC/Al-7Si-Mg (56\% SiC).

It can be seen from the Al-Si phase diagram that, compared with Al-7Si -Mg, Al-12Si$\mathrm{Mg}$ (near eutectic composition point, when little $\mathrm{Mg}$ is ignored) has a lower melting point and better fluidity in $800{ }^{\circ} \mathrm{C}$, which makes it easier to fill the pores of the preform. The difference between the two composites in Figure 8 also confirms this view. In addition, it has been found that the Al-12Si-Mg alloy with high Si content has a low tendency to form $\mathrm{Al}_{4} \mathrm{C}_{3}$. Figure 9 shows the line scan analysis of $\mathrm{SiC} / \mathrm{Al}-7 \mathrm{Si}-\mathrm{Mg}$ and $\mathrm{SiC} / \mathrm{Al}-12 \mathrm{Si}-$ $\mathrm{Mg}$. It shows that the main enrichment peaks of $\mathrm{Si}$ and $\mathrm{C}$ appear simultaneously, and the distribution direction of the peaks is opposite to that of $\mathrm{Al}$, which indicates that they correspond to the $\mathrm{SiC}$ and $\mathrm{Al}$ alloy regions, respectively. As shown in Figure 9a, the line scan analysis shows that $\mathrm{C}$ is enriched at the $\mathrm{SiC} / \mathrm{Al}-7 \mathrm{Si}-\mathrm{Mg}$ interface, and the distribution of $\mathrm{C}$ peak is synchronous with that of $\mathrm{Al}$ peak. It is considered that $\mathrm{Al}_{4} \mathrm{C}_{3}$ is more likely to be generated at the interface. Similar phenomena are rarely observed in $\mathrm{SiC} / \mathrm{Al}-12 \mathrm{Si}-\mathrm{Mg}$ composites. According to the line scan analysis in Figure 9b, there is no C element peak at the interface of $\mathrm{SiC} / \mathrm{Al}-12 \mathrm{Si}-\mathrm{Mg}$ composites, it is considered that the tendency to form $\mathrm{Al}_{4} \mathrm{C}_{3}$ is reduced. Theoretically, it can be seen from the common interfacial reaction (3) that the formation of $\mathrm{Al}_{4} \mathrm{C}_{3}$ is inhibited with the increase in Si content:

$$
4 \mathrm{Al}+3 \mathrm{SiC}=3 \mathrm{Si}+\mathrm{Al}_{4} \mathrm{C}_{3}
$$

From what is mentioned above, the higher thermal conductivity of $\mathrm{SiC} / \mathrm{Al}-12 \mathrm{Si}-\mathrm{Mg}$ composites are mainly attributed to the following: (1) From the Al liquid infiltration behavior, it can be seen from the Al-Si binary phase diagram that the melting point of Al-12Si-Mg is lower than that of Al-7Si-Mg (when the Mg content is negligible). At the same infiltration temperature, the better the fluidity of Al-12Si-Mg, the easier it is to fill the preform. Adequate impregnation improves the density of the composite material which is beneficial to the thermal conductivity. (2) From interface reaction between $\mathrm{SiC}$ and $\mathrm{Al}$, it is considered that the $\mathrm{Al}-12 \mathrm{Si}-\mathrm{Mg}$ alloy with higher Si content has a lower tendency to form $\mathrm{Al}_{4} \mathrm{C}_{3}$ with poor thermal performance, which is beneficial to the thermal conductivity of the composite. The XRD analysis of SiC/ Al-12Si-Mg in Figure 10 also confirmed this view. The diffraction peaks of the composite are mainly composed of the $\mathrm{SiC}$ phase and $\mathrm{Al}$ phase; a small amount of Si phase is also found. 

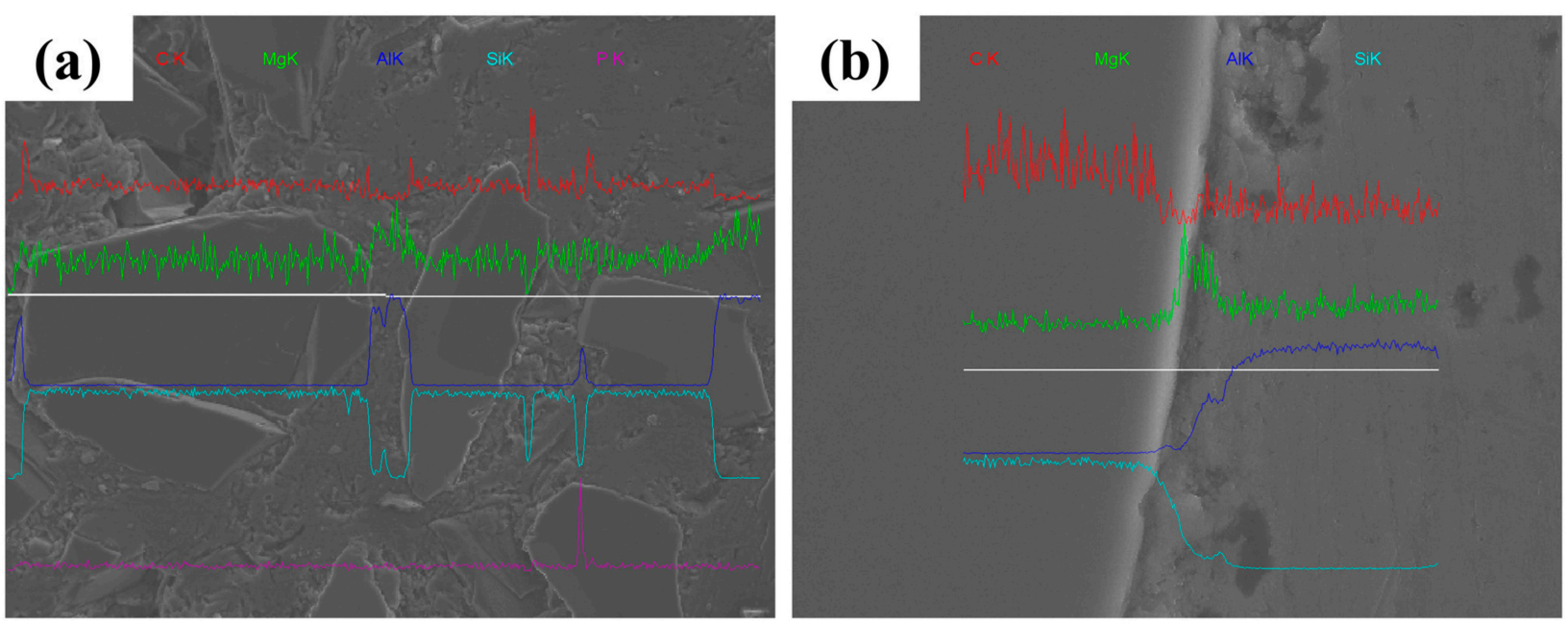

Figure 9. EDS patterns of SiC/Al Composites: (a) SiC/Al-7Si-Mg; (b) SiC/Al-12Si-Mg.

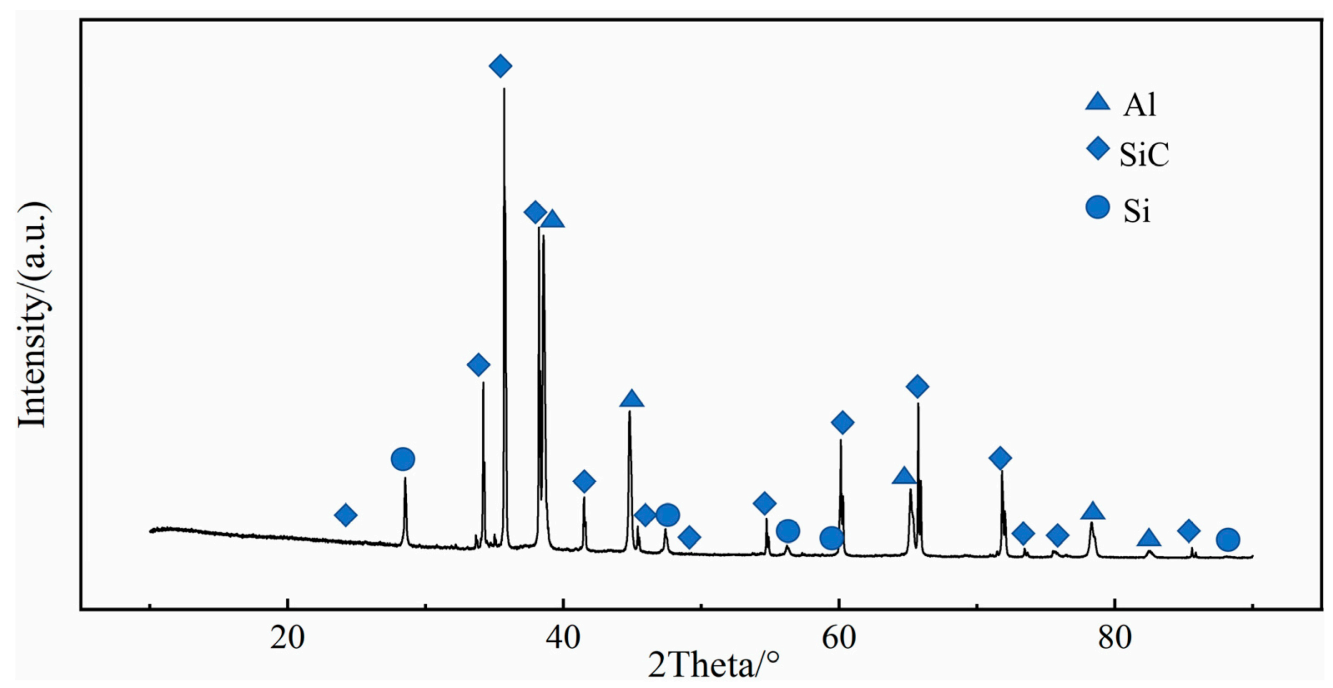

Figure 10. XRD analysis of $\mathrm{SiC} / \mathrm{Al}-12 \mathrm{Si}-\mathrm{Mg}$.

\subsection{Thermal Conductivity of Composites and Its Prediction Model}

In this work, $\mathrm{SiC} / \mathrm{Al}$ composites with different porosity were prepared to study the relationship between porosity and thermal conductivity, as Figure 11 shows. It is easy to find that the increase in porosity will lead to the decrease in thermal conductivity. The thermal conductivity of $\mathrm{SiC} / \mathrm{Al}$ is particularly sensitive to the porosity, especially in the range of $2.5-4.5 \%$. When the porosity is greater than $4.5 \%$, the thermal conductivity decreases at a slower rate. The thermal conductivity of $\mathrm{SiC} / \mathrm{Al}$ composites does not depend entirely on the porosity, it is also related to other factors, such as the thermal conductivity of raw materials, volume fraction of $\mathrm{SiC}$ and the interface combination. The influence of pores on thermal conductivity of $\mathrm{SiC} / \mathrm{Al}$ is analyzed as follows: The thermal conductivity of pore is close to 0 . If it is regarded as dispersed phase, the larger the porosity is, the smaller the thermal conductivity of the composite is. Pores cause strong scattering of phonons and electrons, which hinders heat conduction seriously. The heat flow has to bypass the pores, which undoubtedly increases the length of the heat conduction path, resulting in the decrease in thermal conductivity. In this work, when the porosity is in the range of $2.5-4.5 \%$, it is considered that porosity damage plays the most significant role. The thermal conductivity of the composite decreases greatly with the increase in porosity 
in this range. When the porosity of $\mathrm{SiC} / \mathrm{Al}$ composite is more than $4.5 \%$, The damage of thermal conductivity reduces with the growing porosity.

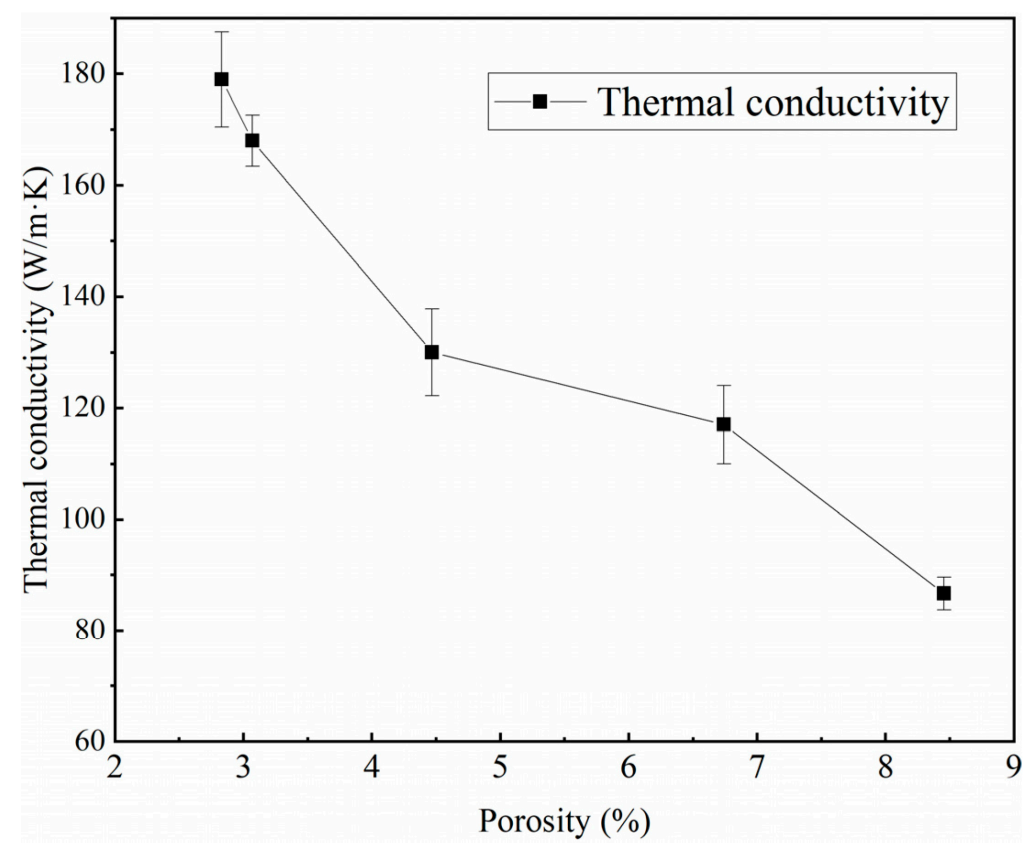

Figure 11. Thermal conductivity of composite materials with different porosity.

Inevitably, pores appear in $\mathrm{SiC} / \mathrm{Al}$ composite materials, especially in $\mathrm{SiC} / \mathrm{Al}$ with a high $\mathrm{SiC}$ volume fraction, for the poor wettability between $\mathrm{SiC}$ and $\mathrm{Al}$. As mentioned above, the thermal conductivity of $\mathrm{SiC} / \mathrm{Al}$ is sensitive to its porosity. With the further study of $\mathrm{SiC} / \mathrm{Al}$ composites, various models have been established to predict the thermal conductivity of the composites. The H-J model considers the influence of interface thermal resistance and particle size on the thermal conductivity, which has been widely used in the field of particle reinforced composites and has achieved good results. In this work, The H-J model is simply applied to establish a new model to study the relationship between porosity and thermal conductivity of $\mathrm{SiC} / \mathrm{Al}$. The mathematical expression of the H-J model is as follows:

$$
K_{\text {eff }}=K_{m} \frac{2 V_{p}\left(\frac{K_{p}}{K_{m}}-\frac{K_{p}}{a h_{c}}-1\right)+\frac{K_{p}}{K_{m}}+2+2 \frac{K_{p}}{a h_{c}}}{V_{p}\left(1-\frac{K_{p}}{K_{m}}+\frac{K_{p}}{a h_{c}}\right)+\frac{K_{p}}{K_{m}}+2+2 \frac{K_{p}}{a h_{c}}}
$$

where $\mathrm{K}_{\text {eff }}$ is the effective thermal conductivity of $\mathrm{SiC} / \mathrm{Al}$ composite; $\mathrm{K}_{\mathrm{m}}$ and $\mathrm{K}_{\mathrm{P}}$ represent the thermal conductivity of $\mathrm{Al}$ alloy and $\mathrm{SiC}$, respectively; $\mathrm{V}_{\mathrm{P}}$ is the volume fraction of $\mathrm{SiC}$; $\mathrm{a}$ is the particle radius of $\mathrm{SiC} ; \mathrm{h}_{\mathrm{c}}$ is the interface thermal conductivity.

Suppose that in the first extreme case, there is no interfacial thermal resistance, i.e., when $\mathrm{h}_{\mathrm{c}} \rightarrow \infty$, the H-J model is expressed as follows:

$$
K_{\infty}=K_{m} \frac{2 V_{p}\left(\frac{K_{p}}{K_{m}}-1\right)+\frac{K_{p}}{K_{m}}+2}{V_{p}\left(1-\frac{K_{p}}{K_{m}}\right)+\frac{K_{p}}{K_{m}}+2}
$$

In the second extreme case, the interfacial thermal resistance is infinite, i.e., $h_{c} \rightarrow 0$, it is equivalent to the case that the particle in the metal matrix is a pore. The expression is as follows:

$$
\mathrm{K}_{0}=\mathrm{K}_{\mathrm{m}} \frac{1-\mathrm{V}_{\mathrm{p}}}{1+0.5 \mathrm{~V}_{\mathrm{p}}}
$$


In this study, use $\lambda_{d}$ as the difference between the actual thermal conductivity of the composite material and the predicted value of the two extreme cases of the H-J model, namely:

$$
\lambda_{\mathrm{d}}=\mathrm{K}_{\infty}+\mathrm{K}_{0}-\mathrm{K}_{\mathrm{a}}
$$

where $\mathrm{K}_{\mathrm{a}}$ is the experimental value of the thermal conductivity of $\mathrm{SiC} / \mathrm{Al}$. In this experiment, the thermal conductivity of $\mathrm{SiC}$ is $220 \mathrm{w} /(\mathrm{m} \cdot \mathrm{K}), \mathrm{a}=50 \mu \mathrm{m}$; the thermal conductivity of Al-7Si-Mg and Al-12Si-Mg calculated by JMatPro are $183.41 \mathrm{w} /(\mathrm{m} \cdot \mathrm{K})$ and $180.66 \mathrm{w} /(\mathrm{m} \cdot \mathrm{K})$, respectively. Using these data, $\mathrm{K}_{\infty}$ and $\mathrm{K}_{0}$ of $\mathrm{SiC} / \mathrm{Al}$, with different porosity, are calculated. After measuring the actual thermal conductivity of each $\mathrm{SiC} / \mathrm{Al}, \lambda_{\mathrm{d}}$ can be obtained according to Equation (7).

The porosity of each composite and its corresponding $\lambda_{d}$ value are shown in Figure 12. The thermal conductivity $\lambda_{d}$ model offers a good agreement with the porosity of highvolume $\mathrm{SiC} / \mathrm{Al}$. Further, the original hypothesis of the theory makes the use of the H-J model limited, that is, the H-J theoretical model has better prediction results and applicability for low volume fraction of $\mathrm{SiC}$. With the increase in the $\mathrm{SiC}$ volume fraction, the theoretical model deviates from the experimental results in application. From Figure 12, the curve of porosity agrees well with the thermal conductivity $\lambda_{d}$ model. It is considered that the introduction of porosity can reduce the limitation of the H-J model. Usually, highvolume $\mathrm{SiC} / \mathrm{Al}$ composites are easier to form pores, due to the poor wettability between matrix and reinforcement phase. Therefore, difficult measurement of $h_{c}$ ignoring the volume fraction of pores (porosity) will limit the application of the H-J model which only considers the volume fraction of $\mathrm{SiC}$ and $\mathrm{Al}$, especially in high-volume fraction $\mathrm{SiC} / \mathrm{Al}$ composites. This also confirms what has been mentioned above, that is, for the high-volume fraction $\mathrm{SiC} / \mathrm{Al}$ with porosity in the range of $2-8 \%$, their thermal conductivity is highly sensitive to porosity. It is considered that porosity is the dominant factor affecting the thermal conductivity. In addition, the consistency of $\lambda_{d}$ and porosity allows us to calculate $\lambda_{d}$ from its corresponding porosity. Through Equation (7), we can further predict $K_{a}$ (the actual thermal conductivity). It is apparent that the good consistency between porosity and the $\lambda_{d}$ model indirectly reflects the consistency between the porosity and $K_{a}$. Therefore, through the $\lambda_{d}$ model, it is easy and precise to predict the actual thermal conductivity $K_{a}$ of $\mathrm{SiC} / \mathrm{Al}$ by measuring the porosity but $\mathrm{h}_{\mathrm{c}}$. In this paper, the $\lambda_{\mathrm{d}}$ model can be regarded as a bridge, which is more accurate to connect the thermal conductivity and porosity of high-volume fraction $\mathrm{SiC} / \mathrm{Al}$ composites. It should be emphasized that this prediction prefers high-volume fraction $\mathrm{SiC} / \mathrm{Al}$ composites with porosity in the range of $2-8 \%$.

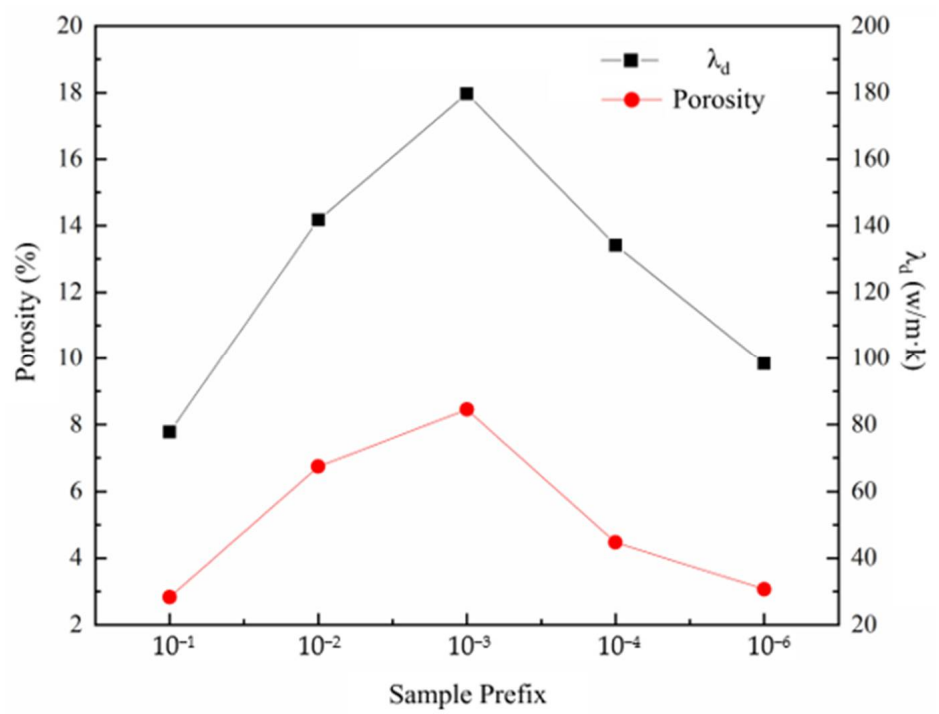

Figure 12. The porosity of each composite and its corresponding $\lambda_{d}$ value. 


\section{Conclusions}

In this study, the preparation process and thermal conductivity of high-volume fraction $\mathrm{SiC} / \mathrm{Al}$ composites by vacuum pressure infiltration were investigated, and the main conclusions are as follows:

- The volume fraction of SiC can be adjusted regularly by using $12 \mu \mathrm{m}$ and $100 \mu \mathrm{m} \mathrm{SiC}$ particles with different proportions. When the proportion of $100 \mu \mathrm{m} \mathrm{SiC} \mathrm{particles} \mathrm{is}$ about $77 \%$, the volume fraction of $\mathrm{SiC}$ reaches the maximum. The introduction of small particles easily causes the pore size of the $\mathrm{SiC}$ preform to shrink, which requires greater infiltration pressure to prepare $\mathrm{SiC} / \mathrm{Al}$ composites.

- The porosity of the $\mathrm{SiC}$ preform can be adjusted stably by adding pore forming agent $\mathrm{NH}_{4} \mathrm{HCO}_{3}$, which satisfies the following mathematical model: $\mathrm{Y}=26.9+0.4 \mathrm{X}$. It is understood that $\mathrm{NH}_{4} \mathrm{HCO}_{3}$ acts as a bridge to connect more pores in the preform, which is conducive to the subsequent infiltration process.

- Compared with Al-7Si-Mg, Al-12Si-Mg shows better infiltration results. The main reasons are as follows: First, Al-12Si-Mg is infiltrated fully for the best fluidity and low infiltration resistance. In addition, it is considered that $\mathrm{Al}-12 \mathrm{Si}-\mathrm{Mg}$ with high $\mathrm{Si}$ content has little tendency to form harmful phase $\mathrm{Al}_{4} \mathrm{C}_{3}$, which is beneficial to achieve good infiltration results.

- The thermal conductivity of high-volume fraction $\mathrm{SiC} / \mathrm{Al}$ is sensitive to their porosity, especially when the porosity is in the range of $2.5-4.5 \%$. Through the newly established $\lambda_{\mathrm{d}}$ model and its connection with the porosity, the thermal conductivity of highvolume fraction $\mathrm{SiC} / \mathrm{Al}$ with $2-8 \%$ porosity can be effectively predicted.

Author Contributions: Conceptualization, Y.B. and Z.Z.; methodology, M.C., Y.B. and Z.Z.; software, M.C.; validation, M.C., Y.B., Z.Z. and H.Z.; formal analysis, M.C.; investigation, M.C. and Y.B; resources, Y.B., Z.Z. and H.Z.; data curation, M.C.; writing—original draft preparation, M.C.; writingreview and editing, M.C., Y.B. and Z.Z.; visualization, M.C.; supervision, Y.B. and Z.Z.; project administration, Y.B. and Z.Z.; funding acquisition, Y.B. and Z.Z. All authors have read and agreed to the published version of the manuscript.

Funding: This research received no external funding.

Institutional Review Board Statement: Not applicable.

Informed Consent Statement: Not applicable.

Data Availability Statement: Data is contained within the article.

Acknowledgments: The authors acknowledge General Research Institute for Nonferrous Metals for its innovation fund support, as well as the research platform of National Engineering \& Technology Research Center for Nonferrous Metals Composites and National Engineering Reseach Center for Metallic Materials Net-shape Forming for their technical support. Grinm Metal Composites Technology Co., Ltd. is greatly acknowledged.

Conflicts of Interest: The authors declare no conflict of interest.

\section{References}

1. Cui, Y. Microstructural Characterization and Properties of SiC/Al Composites for Electronic Packaging Fabricated by Pressureless Infiltration. Mater. Sci. Forum 2007, 546-549, 1597-1602. [CrossRef]

2. Lee, H.; Jeon, K.; Kim, H.; Hong, S. Fabrication process and thermal properties of SiCp/Al metal matrix composites for electronic packaging applications. J. Mater. Sci. 2000, 35, 6231-6236. [CrossRef]

3. Li, S.; Xiong, D.; Liu, M.; Bai, S.; Zhao, X. Thermophysical properties of SiC/ Al composites with three dimensional interpenetrating network structure. Ceram. Int. 2014, 40, 7539-7544. [CrossRef]

4. Zhang, Z.; Shi, Z.; Yang, B.; Ge, B.; Zhang, X.; Guo, Y. Preparation and anisotropic thermophysical properties of SiC honeycomb/AlMg-Si composite via spontaneous infiltration. Prog. Nat. Sci. Mater. 2019, 2, 177-183. [CrossRef]

5. Liu, J.; Zheng, Z.; Wang, J.; Wu, Y.; Tang, W.; Lv, J. Pressureless infiltration of liquid aluminum alloy into SiC preforms to form near-net-shape SiC/Al composites. J. Alloys Comp. 2008, 465, 239-243. [CrossRef]

6. Sun, J.; Chen, G.; Wang, B.; Chen, G.; Tang, W. Fabrication, Microstructures, and Properties of 50 vol.\% SiCp/6061Al Composites via Hot Pressing. J. Mater. Eng. Perform. 2019, 5, 2697-2706. [CrossRef] 
7. Sijo, M.; Jayadevan, K. Analysis of Stir Cast Aluminium Silicon Carbide Metal Matrix Composite: A Comprehensive Review. Procedia Technol. 2016, 2016, 379-385. [CrossRef]

8. Zhu, J.; Wang, F.; Wang, Y.; Zhang, B.; Wang, L. Interfacial structure and stability of a co-continuous SiC/Al composite prepared by vacuum-pressure infiltration. Ceram. Int. 2017, 43, 6563-6570. [CrossRef]

9. Peng, J. Research on Preparation of SiCp Porous Preform and Vacuum Pressure Infiltration of Liquid Aluminum Alloys. Master's Thesis, South China University of Technology, Guangzhou, China, 2017.

10. Xie, B.; Zhao, H.; Long, H.; Peng, J.; Liu, R. 3D characteristics of pores in SiC particle preforms with different starch contents by X-ray micro-computed tomography. Ceram. Int. 2019, 18, 23924-23933. [CrossRef]

11. Long, H.; Zhao, H.; Peng, J.; Liu, R. Effect of particle size on $3 \mathrm{D}$ characteristics of pores in $\mathrm{SiC}_{\mathrm{p}}$ preforms. Acta Mater. Compos. Sin. 2017, 34, 599-607.

12. Graton, L.; Fraser, H. Systematic Packing of Spheres: With Particular Relation to Porosity and Permeability. J. Geol. 1935, 43, 785-909. [CrossRef]

13. Yu, A.; Standish, N. Estimation of the porosity of particle mixtures by a linear-mixture packing model. Ind. Eng. Chem. Res. 1991, 30, 1372-1385. [CrossRef]

14. Wang, Q.; Wu, Y.; Pan, R. Effect of pore-forming agent on microstructure and thermal conductivity of $\mathrm{SiC}_{\mathrm{p}} / \mathrm{Al}$ composites prepared by pressureless infiltration. Chin. J. Nonferrous Met. 2010, 20, 2162-2167.

15. Molina, J.; Saravanan, R.; Arpón, R.; García-Cordovilla, C.; Louis, E.; Narciso, J. Pressure infiltration of liquid aluminium into packed $\mathrm{SiC}$ particulate with a bimodal size distribution. Acta Mater. 2002, 50, 247-257. [CrossRef]

16. Liu, T.; Cai, X.; He, L.; Li, G. Effect of Pore-forming Agents Content on Porosity and Experimental Study on Porosity Measurement of Porous SiC Prefrom. Mater. Rev. 2013, 27, 108-112.

17. Wang, D.; Zheng, Z.; Lv, J.; Xu, G.; Zhou, S.; Tang, W.; Wu, Y. Interface Design in 3D-SiC/Al-Si-Mg Interpenetrating Composite Fabricated by Pressureless Infiltration. Ceram. Int. 2018, 44, 11956-11965. [CrossRef]

18. Zhang, Q.; Ma, X.; Wu, G. Interfacial microstructure of $\mathrm{SiCp} / \mathrm{Al}$ composite produced by the pressureless infiltration technique. Ceram. Int. 2013, 39, 4893-4897. [CrossRef]

19. Wang, X.; Ren, H.; Zhu, M.; Zhu, M.; Deng, L. The Research of $\beta$-SiCp/Al Electronic Packaging Composites Fabricated by Pressureless Infiltrating. Adv. Mater. Res 2012, 490-495, 3816-3821. [CrossRef]

20. Ren, S.; He, X.; Qu, X.; Li, Y. Effect of controlled interfacial reaction on the microstructure and properties of the SiCp/Al composites prepared by pressureless infiltration. J. Alloys Comp. 2008, 455, 424-431. [CrossRef]

21. Lee, H.; Hong, S. Pressure infiltration casting process and thermophysical properties of high volume fraction $\mathrm{SiCp} / \mathrm{Al} \mathrm{metal}$ matrix composites. Mater. Sci. Tech. 2003, 19, 1057-1064. [CrossRef]

22. Molina, J.; Prieto, R.; Narciso, J.; Louis, E. The effect of porosity on the thermal conductivity of Al-12wt.\% Si/SiC composites. Scripta Mater. 2009, 60, 582-585. [CrossRef]

23. Shen, Y. Combined effects of microvoids and phase contiguity on the thermal expansion of metal-ceramic composites. Mater. Sci. Eng. A 1997, 237, 102-108. [CrossRef]

24. Zhou, X.; Wu, K.; Zou, X.; Hua, X.; Que, Y. Effect of porosity on thermal conductivity of $\mathrm{SiC}_{\mathrm{P}} / \mathrm{Al}$ composites. T. Mater. Heat Treat. 2015, 36, 236-240.

25. Haselman, D.; Donaldson, K. Effect of Reinforcement Particle Size on the Thermal Conductivity of a Particulate-Silicon CarbideReinforced Aluminum Matrix Composite. J. Am. Ceram. Soc. 1992, 75, 3137-3140. [CrossRef]

26. Kawai, C. Effect of Interfacial Reaction on the Thermal Conductivity of Al-SiC Composites with SiC Dispersions. J. Am. Ceram. Soc. 2001, 84, 896-898. [CrossRef]

27. Hasselman, D.; Johnson, L. Effective Thermal Conductivity of Composites with Interfacial Thermal Barrier Resistance. J. Compos. Mater. 1987, 21, 508-515. [CrossRef]

28. Hamman, N.; Fleming, J.; Schlueter, E.; Janson, I.; Meridew, J.; Kumar, M. Method and Apparatus for Forming Porous Metal Implants. European Patent EP 1996248B1, 4 April 2016. Available online: https:/ / www.freepatentsonline.com/EP1996248.html (accessed on 27 April 2021).

29. Chen, M.; Bai, Y.; Zhang, Z.; Zheng, H.; Zhang, Z. Study on Preparation of SiC Preform for Electronic Packaging Material. In Proceedings of the 2020 21st International Conference on Electronic Packaging Technology (ICEPT), Guangzhou, China, 12-15 August 2020; IEEE: New York, NY, USA, 2020; pp. 1-5.

30. McGeary, R. Mechanical Packing of Spherical Particles. J. Am. Ceram. Soc. 1961, 44, 513-522. [CrossRef]

31. Wang, D.; Zheng, Z.; Lv, J.; Xu, G.; Zhou, S.; Tang, W.; Wu, Y. Multimodal particle distribution in 3D-SiC/Al-Si-Mg interpenetrating composite fabricated by pressureless infiltration. Ceram. Int. 2018, 16, 19851-19858. [CrossRef]

32. Molina, J.; Piñero, E.; Narciso, J.; García-Cordovilla, C.; Louis, E. Liquid metal infiltration into ceramic particle preforms with bimodal size distributions. Curr. Opin. Solid State Mater. Sci. 2005, 9, 202-210. [CrossRef]

33. Delannay, F.; Froyen, L.; Deruyttere, A. The wetting of solids by molten metals and its relation to the preparation of metal-matrix composites. J. Mater. Sci. 1987, 1, 1-16. [CrossRef] 